ing laws. The building has the ordinary studding, about 4 feet apart, covered with tarred paper; over the tarred paper chicken fencing wire with open mesh is placed. On this is squirted a mixture of sand, cement and water, the mixture in one hose, and water in the other hose. It is fire-proof and, if necessary, can be made water-proof, and if you want to pull it down you can do so with a pickaxe. The walls of cement are made $1 / 4$ inch thick on either side. The cement may be a beautiful white or gray color, and is practically impervious to moisture. The two hoses are carried around easily; the sand nozzle is lined with rubber; the sand does not affect the rubber as it does a nozzle made of steel without the rubber protection. The man stands and squirts this mixture on as you squirt with a garden hose. A square yard of surface is covered in a couple of minutes.

\section{NEW USES TO REDUCE ABUSES IN CONSERVATION.}

By W. R. Whitney.

I believe the unmodified word conservation is an unfortunate choice. To conserve is "to keep from loss, decay or injury: to preserve." Conservation is defined as the act of conserving, and to be conservative is to be "adhering to the existing order of things, opposed to change or progress." No good research chemist can afford to stop at such conservation. There is an active as there is a passive conservation; this could probably be defined as efficient utility. Considering the mineral resources of our country, we will concern ourselves with the maximum in efficient utility or be left behind. A certain wellknown Corsican once said: "You cannot make an omelet without breaking an egg." There are plenty of signs that birth and growth in everything calls for the breaking of eggs and the question of efficiency is the one of interest. If you merely save your eggs, they will rot. I have collected a very few of the cases illustrating the trend of chemical work towards such active conservation.

During the past ten to twenty years, the chemists have been developing new uses for new materials very rapidly. A few years ago titaniferous iron ores were useless. Today those containing the highest proportion of titanium oxide are being mined and the ferro-titanium sold by the thousand tons. A few years ago quartz could hardly have been considered an ore. Today thousands of tons of silicon and ferrosilicon are being sold annually.

A few years ago tantalum and columbium ores were merely of interest as museum specimens. Now they are being worked for the tantalum, and doubtless the niobium will soon be utilized.

A few years ago rutile was used only in collections of minerals. It is now mined in large quantities and used in various forms in arc lamps and ought to find use in alloys.

A few years ago chromium had little use and metallic manganese was a curiosity. Now the two metals are used by the ton as pure metals in alloys for electrical resistance. They replace much greater quantities of German silver and other expensive alloys.

Ten years ago tungsten was conserved in tool steels only, while today it is saving the equivalent of millions of dollars annually in power used for lighting.

A few years ago emery was mined and was our best abrasive. Today we have artificial fused alumina and artificial carborundum, and emery is being conserved for those who later may want to see the natural material. Here, too, time and energy are being conserved with the same output of grinding.

A few years ago extensive mining operations had to be carried on to supply the graphite we use. Today that material is artificially produced from coal, which can be mined very much more economically.

It is not far back to the time when aluminum was brought into use. It now greatly helps the conservation of copper.

Poor farming land in our southern states is being worked for monazite sand, and our houses are being lighted by its use in gas mantles. This use of an ore is of our decade.

\section{MINERAL LOSSES IN GASES AND FUMES.}

By F. G. COTTRELL.

In considering the mineral wastes passing out of the stacks of our smelters and metal refineries, we must distinguish clearly between the gases themselves and the clouds of suspended solid and liquid particles which they mechanically carry along with them. In which class a material belongs, often depends, to be sure, on temperature. Many metallic compounds are actually vaporized in the furnaces and gradually condense from gases into clouds of solid particles with the progressive cooling of the gas streaming through the flues. Arsenic in the form of the trioxide is usually the last of these materials to condense, since even down to $150^{\circ}$ its vapor tension is sufficient to permit the loss, in the gaseous state, of several tons a day from the largest plants. But below, say I $25^{\circ} \mathrm{C}$., we may fairly consider for ordinary technical purposes that the only important element in the gaseous state is sulfur, in the form of dioxide. Detailed consideration of these losses of solids is given elsewhere in this issue of THISJOURNAL as well as in a previous article by the author ${ }^{r}$ and still earlier by W. C. Ebaugh. ${ }^{2}$

For many centuries the material nature of gases and the fact that they actually possess weight escaped the chemist. Even to-day a distinct effort of mind is required to sense the vast tonnage of the clouds we see floating away so lightly from smelter and power-house stacks. There are many single stacks in this country, from each of which over five tons of gas issue per minute, while in isolated instances this is exceeded several-fold.

Aside from carbon, the element which is lost in the greatest tonnage is unquestionably sulfur. Many of our western ores will run from 25 to nearly $4 \circ$ per cent. sulfur and a plant smelting $I, 000$ tons of ore per day is at present considered to have a very moderate capacity. The largest plants will easily touch

1 This Journal, 3, 543-550 (Aug., 1911).

2 Ibid., 1, 686-689 (Oct., 1909) and 2, 372-3 (Sept., 1910). 